\title{
Polymer-Caged Liposomes: A pH-Responsive Delivery System with High Stability
}

\author{
Sang-Min Lee, Haimei Chen, Christine M. Dettmer, Thomas V. O'Halloran*, and SonBinh T. Nguyen* \\ Department of Chemistry \& the Center for Cancer Nanotechnology Excellence, Northwestern University, Evanston IL 60208 USA \\ E-mail: stn@northwestern.edu; t-ohalloran@northwestern.edu
}

Materials. 2,2,5-Trimethyl-4-phenyl-3-azahexane-3-oxy radical 2 was synthesized using a reported literature procedure. ${ }^{1} 1,2$-dipalmitoyl$s n$-glycero-3-phosphocholine (DPPC) and 1,2-dioleoyl-sn-glycero-3-[phospho-rac-(1-glycerol)] (sodium salt) (DOPG) were purchased from Avanti Polar Lipids (Alabaster, AL). ICP calibration standard solutions of phosphorus (1000 $\mu \mathrm{g} / \mathrm{mL}$ P), 1-(3-dimethylaminopropyl)3 -ethylcarbodiimide methiodide (EDC·MeI), and all other reagents, buffer mixes, and solvents were purchased from the Aldrich Chemical Company and used as received. Tert-butyl acrylate was stirred over $\mathrm{CaH}_{2}$ under nitrogen and fractionated by vacuum transfer right before use. Nanopure water was obtained from a Millipore system (18.2 $\mathrm{M} \Omega \mathrm{cm}$ resistivity).

For syntheses, HPLC-grade tetrahydrofuran (THF, Fisher Scientific) was dried over neutral alumina via the Dow-Grubbs solvent system $^{2}$ installed by Glass Contours (Laguna Beach, CA). The solvent was collected under argon, degassed under vacuum, and stored under nitrogen in a Straus flask prior to use. ACS-grade benzene, chloroform, methylene chloride, ethyl acetate, acetone and methanol were obtained from commercial sources (either Fisher Scientific or VWR) used without further purifications. Deuterated solvents (Cambridge Isotope Laboratories) was purchased from commercial sources and used as received. All flash chromatography was carried out using a 56-mm inner diameter column containing 200-mm of silica gel (230-400 mesh, purchased from Sorbent Technologies; Atlanta, GA) under a positive pressure of lab air. Spectra/Por Cellulose Ester (CE) dialysis membranes were purchased from Spectrum Laboratories (Rancho Dominguez, CA). Liposome extruder and extrusion membranes were also purchased from Avanti Polar Lipids (Alabaster, AL). Vortexing of solutions was carried out using a Vortex Mixer (American Hospital Supply Corp. McGrow Park, IL) set at 5.5 setting.
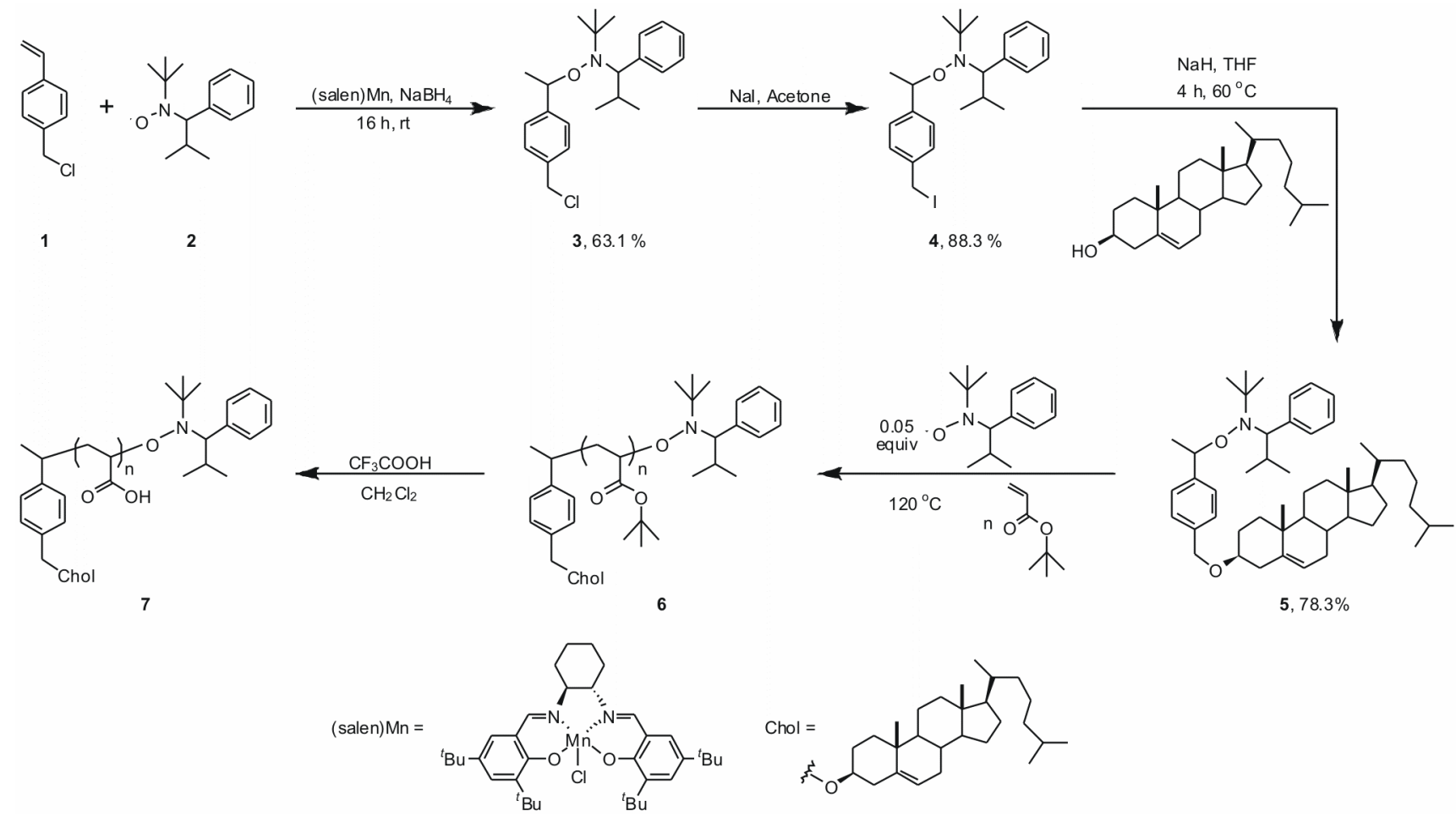

Figure S1. Synthesis of cholesterol-terminated poly(acrylic acid).

Preparation of $N$-tert-Butyl- $O$-[1-(4-chloromethyl-phenyl)-ethyl]- $N$-(2-methyl-1-phenyl-propyl)-hydroxylamine (3). Chloromethyl alkoxyamine initiator 3 was prepared using a modified literature procedure. ${ }^{3}$ To a $100-\mathrm{mL}$ round-bottom flask equipped with a magnetic stirbar was added 2 (1.257 g, $5.0 \mathrm{mmol})$, p-vinyl benzyl chloride 1 (1.526 g, $10.0 \mathrm{mmol})$, and a mixture of benzene/ethanol (1:1 v/v, 30 $\mathrm{mL})$. To the resulting solution was then added $[(\mathrm{S}, S)-(+)-1,2$-cyclohexanediamino- $N, N$ '-bis(3,5-di-tert-butylsalicylidene) $]$ manganse(III) chloride (476.4 mg, $0.75 \mathrm{mmol})$ followed by sodium borohydride $(378.3 \mathrm{mg}, 10.0 \mathrm{mmol})$. The reaction mixture was then capped with a rubber steptum containing a needle vent and allowed to stir for 15 hours at room temperature with a slow bubbling of air directly into the 
reaction using a 22-gauge needle (care must be taken with the bubbling rate ( 2 bubbles/s) so as not to evaporate the solvent over the length of the reaction).

After the reaction, the solvent was concentrated on a rotary evaporator. The resulting oily crude product was dissolved in dichloromethane $(\sim 50 \mathrm{~mL})$ and washed with deionized water $(3 \times 50 \mathrm{~mL})$. The organic layer was again concentrated to a minimum on a rotary evaporator and purified by flash chromatography, eluting with $2 \%$ ethyl acetate in hexanes. The desired chloromethyl alkoxyamine 3 was obtained as a colorless oil $\left(1.179 \mathrm{~g}, 63.1 \%\right.$ yield). $\operatorname{IR}\left(\mathrm{CH}_{2} \mathrm{Cl}_{2}\right): 2974,2866,1451,1384,1360,1264,1206,1060,837,701,679 \mathrm{~cm}$ ${ }^{1}$. ${ }^{1} \mathrm{H}$ NMR $\left(500 \mathrm{MHz}, \mathrm{CDCl}_{3}\right.$, both diastereomers): $\delta 7.5-7.1(\mathrm{~m}, 18 \mathrm{H}$, both diastereomers), $4.94(\mathrm{q}+\mathrm{q}, 2 \mathrm{H}, J=6.4 \mathrm{~Hz}$, both diastereomers), $4.63(\mathrm{~s}, 2 \mathrm{H}$, major diastereomer), $4.60(\mathrm{~s}, 2 \mathrm{H}$, minor diastereomer), $3.43(\mathrm{~d}, 1 \mathrm{H}, J=10.0 \mathrm{~Hz}$, minor diastereomer), $3.32(\mathrm{~d}$, $1 \mathrm{H}, J=11.2 \mathrm{~Hz}$, major diastereomer), $2.35(\mathrm{~m}, 2 \mathrm{H}$, both diastereomers), 1.64 (d, 3H, $J=6.4 \mathrm{~Hz}$, minor diastereomer), $1.56(\mathrm{~d}, 3 \mathrm{H}, J=6.0$ $\mathrm{Hz}$, major diastereomer), 1.32 (d, $3 \mathrm{H}, J=6.8 \mathrm{~Hz}$, minor diastereomer), 1.06 (s, 9H, major diastereomer), $0.94(\mathrm{~d}, 3 \mathrm{H}, J=6.0 \mathrm{~Hz}, \mathrm{major}$ diastereomer), $0.80(\mathrm{~s}, 9 \mathrm{H}$, minor diastereomer $), 0.56(\mathrm{~d}, 3 \mathrm{H}, J=6.4 \mathrm{~Hz}$, minor diastereomer $), 0.25(\mathrm{~d}, 3 \mathrm{H}, J=6.8 \mathrm{~Hz}, \mathrm{major}$ diastereomer). ${ }^{13} \mathrm{C} \mathrm{NMR} \mathrm{(125} \mathrm{MHz,} \mathrm{CDCl}_{3}$, both diastereomers): $\delta 146.3,145.5,142.5,142.3,136.6,135.8,131.1,128.6,127.5,127.4$, 126.6, 126.5, 126.3, 83.3, 82.4, 72.3, 60.7, 60.6, 46.4, 32.2, 31.8, 28.6, 28.4, 24.9, 23.3, 22.3, 22.1, 21.3, 21.2. Anal.: Calcd for $\mathrm{C}_{23} \mathrm{H}_{32} \mathrm{NOCl}\left(1 / 2 \mathrm{C}_{6} \mathrm{H}_{14}\right): \mathrm{C}, 74.70 ; \mathrm{H}, 9.64 ; \mathrm{N}, 3.35$; Found: $\mathrm{C}, 74.56, \mathrm{H}, 9.21, \mathrm{~N}, 3.27$. ESIMS: $\mathrm{m} / \mathrm{z}=374.03$ observed for $\mathrm{M}^{+} ; 373.22$ calculated.

Preparation of $\boldsymbol{N}$-tert-Butyl- $\boldsymbol{O}$-[1-(4-iodomethyl-phenyl)-ethyl]- $\boldsymbol{N}$-(2-methyl-1-phenyl-propyl)-hydroxylamine (4). To a 50-mL round-bottom flask equipped with a magnetic stirbar was added chloromethyl alkoxyamine $\mathbf{3}(1.789 \mathrm{~g}, 4.784 \mathrm{mmol})$ and acetone $(20 \mathrm{~mL})$. To the resulting solution was added sodium iodide $(2.869 \mathrm{~g}, 19.14 \mathrm{mmol}, 4$ equiv) and the reaction mixture was capped with a rubber septum and allowed to stir for 24 hours at room temperature. The sodium chloride side product was remove by gravity filtration, and the filtrate was concentrated on a rotary evaporator. The crude oily product was purified by flash chromatography, eluting with hexanes. The desired iodomethyl akoxyamine 4 was obtained as a colorless oil (1.968 g, $88.3 \%$ yield). $\operatorname{IR}\left(\mathrm{CH}_{2} \mathrm{Cl}_{2}\right): 2970,2864,1451,1384,1360$, 1206, 1156, 1059, 701, $582 \mathrm{~cm}^{-1}$. ${ }^{1} \mathrm{H}$ NMR $\left(500 \mathrm{MHz}, \mathrm{CDCl}_{3}\right.$, both diastereomers): $\delta 7.5-7.1(\mathrm{~m}, 18 \mathrm{H}$, both diastereomers), $4.93(\mathrm{q}+\mathrm{q}$, $2 \mathrm{H}, J=6.4 \mathrm{~Hz}$, both diastereomers), $4.52(\mathrm{~s}, 2 \mathrm{H}$, major diastereomer), $4.48(\mathrm{~s}, 2 \mathrm{H}$, minor diastereomer), $3.46(\mathrm{~d}, 1 \mathrm{H}, J=10.0 \mathrm{~Hz}, \mathrm{minor}$ diastereomer), $3.33(\mathrm{~d}, 1 \mathrm{H}, J=10.5 \mathrm{~Hz}$, major diastereomer), $2.38(\mathrm{~m}, 2 \mathrm{H}$, both diastereomer), $1.65(\mathrm{~d}, 3 \mathrm{H}, J=6.0 \mathrm{~Hz}, \mathrm{minor}$ diastereomer), 1.57 (d, $3 \mathrm{H}, J=6.5 \mathrm{~Hz}$, major diastereomer), 1.34 (d, 3H, $J=6.5 \mathrm{~Hz}$, minor diastereomer), 1.08 (s, 9H, major diastereomer), $0.94(\mathrm{~d}, 3 \mathrm{H}, J=6.0 \mathrm{~Hz}$, major diastereomer), $0.82(\mathrm{~s}, 9 \mathrm{H}$, minor diastereomer), $0.58(\mathrm{~d}, 3 \mathrm{H}, J=6.0 \mathrm{~Hz}$, minor diastereomer), $0.26\left(\mathrm{~d}, 3 \mathrm{H}, J=6.5 \mathrm{~Hz}\right.$, major diastereomer). ${ }^{13} \mathrm{C} \mathrm{NMR}\left(125 \mathrm{MHz}, \mathrm{CDCl}_{3}\right.$, both diastereomers): $\delta 145.7,144.9,142.4$, 138.5, 137.6, 135.8, 131.1, 128.9, 127.7, 127.6, 127.4, 126.8, 126.6, 126.4, 83.3, 82.5, 72.3, 60.6, 32.0, 28.5, 24.7, 23.0, 22.3, 21.3, 6.2. Anal.: Calcd for $\mathrm{C}_{23} \mathrm{H}_{32} \mathrm{NOI}\left(1 / 2 \mathrm{C}_{6} \mathrm{H}_{14}\right)$ : C, 61.53; H, 7.55; N, 2.76; Found: $\mathrm{C}, 62.16, \mathrm{H}, 7.26$, N, 3.14. ESIMS: $\mathrm{m} / \mathrm{z}=465.95$ observed for $\mathrm{M}^{+} ; 465.41$ calculated.

Preparation of $\mathrm{N}$-tert-Butyl- $\mathrm{O}$-[1-(4-cholesterolmethyl-phenyl)-ethyl]- $\mathrm{N}$-(2-methyl-1-phenyl-propyl)-hydroxylamine (5). Inside a drybox, sodium hydride $(51.5 \mathrm{mg}, 2.146 \mathrm{mmol})$ was added to a $50-\mathrm{mL}$ two-neck flask equipped with a magnetic stirbar and a water-cooled reflux condenser. The flask was capped with a rubber septum, taken out of the drybox, and attached to a Schlenk line and a water line. Anhydrous tetrahydrofuran $(20 \mathrm{~mL})$ was then added to make a suspension.

Into a 50-mL Schlenk flask equipped with a magnetic stirbar was added iodomethyl alkoxyamine 4 (500 $\mathrm{mg}, 1.073 \mathrm{mmol})$. Into a second Schlenk flask equipped with a magnetic stirbar was added cholesterol (414.9 mg, $1.073 \mathrm{mmol})$. Both flasks were evacuated and back filled with nitrogen on a 50-mL Schlenk line three times before dry tetrahydrofuran ( $1 \mathrm{~mL}$ for the second flask and $5 \mathrm{~mL}$ for the third) were injected via a gas-tight syringe. The cholesterol solution in the second Schlenk flask was then transferred into the NaH suspension using a cannula. The resulting mixture was stirred at room temperature under nitrogen for 20 min when the alkoxyamine solution from the first Schlenk flask was added dropwise to it via a gas-tight syringe. The reaction mixture was next heated at reflux for 5 hours at $60{ }^{\circ} \mathrm{C}$ and then transferred into a 50-ml round-bottom flask. After the solvent was evaporated on a rotary evaporator, the resulting oily crude product was dissolved in dichloromethane $(\sim 50 \mathrm{~mL})$ and washed with deionized water $(3 \mathrm{x} 50 \mathrm{~mL})$. The organic layer was again concentrated to a minimum on a rotary evaporator and purified by flash chromatography, eluting with $1 \%$ ethyl acetate in hexanes. The cholesterolmodified alkoxyamine 5 was isolated as a colorless oil (609 mg, $78.3 \%$ yield). $\operatorname{IR}\left(\mathrm{CH}_{2} \mathrm{Cl}_{2}\right): 2971,2865,1465,1451,1381,1361,1206$, $1085,1062,820,739,701 \mathrm{~cm}^{-1}$. ${ }^{1} \mathrm{H} \mathrm{NMR}\left(500 \mathrm{MHz}, \mathrm{CDCl}_{3}\right.$, both diastereomers): $\delta 7.5-7.1(\mathrm{~m}, 18 \mathrm{H}$, both diastereomers), $5.33(\mathrm{t}, 2 \mathrm{H}, J=$ $4.5 \mathrm{~Hz}$, both diastereomers), $4.91(\mathrm{~m}, 2 \mathrm{H}$, both diastereomers), $4.58(\mathrm{~s}, 2 \mathrm{H}$, minor diastereomers), 4.52 (s, 2H, major diastereomers), 3.53 $(\mathrm{q}+\mathrm{q}, 2 \mathrm{H}, J=7.5 \mathrm{~Hz}$, both diastereomers), $3.41(\mathrm{~m}, 1 \mathrm{H}$, minor diastereomer), $3.27(\mathrm{~m}, 1 \mathrm{H}$, major diastereomer), $2.41(\mathrm{~m}, 2 \mathrm{H}$, both diastereomers), 2.35-2.25 (m, 4H, both diastereomers), 2.01-1.94 (m, 4H, both diastereomers), 1.87-1.80 (m, 6H, both diastereomers), 1.61 (d, $3 \mathrm{H}, J=4.5 \mathrm{~Hz}$, minor diastereomer), 1.53 (d, 3H, $J=4.5 \mathrm{~Hz}$, major diastereomer), 1.55-1.43 (m, 18H, both diasteromers), $1.35-1.24$ $(\mathrm{m}, 6 \mathrm{H}$, both diastereomers), $1.29(\mathrm{~d}, 3 \mathrm{H}, J=6.0 \mathrm{~Hz}$, minor diastereomer), 1.04 (s, 9H, major diastereomer), 1.00 (s, 6H, both diastereomers), $0.92(\mathrm{~d}, 3 \mathrm{H}, J=4.5 \mathrm{~Hz}$, major diastereomer), $0.91(\mathrm{~d}, 6 \mathrm{H}, J=6.0 \mathrm{~Hz}$, both diastereomers $), 0.86(\mathrm{~d}+\mathrm{d}, 12 \mathrm{H}, J=6.0 \mathrm{~Hz}$, both diastereomers), $0.78(\mathrm{~s}, 9 \mathrm{H}$, minor diastereomers), $0.67(\mathrm{~s}, 12 \mathrm{H}$, both diastereomers), 0.54 (d, $3 \mathrm{H}, J=4.5 \mathrm{~Hz}$, minor diastereomer), $0.21\left(\mathrm{~d}, 3 \mathrm{H}, J=4.5 \mathrm{~Hz}\right.$, major diastereomer). ${ }^{13} \mathrm{C} \mathrm{NMR}\left(125 \mathrm{MHz}, \mathrm{CDCl}_{3}\right.$, both diastereomers): $\delta 145.2,144.4,142.6,142.5,141.2$, $141.1,138.2$, 137.4, 131.1, 127.6, 127.5, 127.4, 127.2, 127.1, 126.5, 126.3, 121.8, 121.7, 83.5, 82.7, 78.9, 78.5, 78.3, 72.8, 72.3, 70.1, 69.9, 65.9, 65.6, 60.7, 57.0, 56.3, 50.4, 42.5, 40.0, 39.7, 39.4, 37.5, 37.1, 36.4, 36.0, 32.2, 32.1, 32.0, 31.9, 28.6, 28.4, 28.2, 25.0, 24.5, 24.0, 23.4, 23.0, 22.8, 22.3, 22.2, 21.3, 19.6, 18.9,15.5, 12.1. Anal.: Calcd for $\mathrm{C}_{50} \mathrm{H}_{77} \mathrm{NO}_{2}$ : C, 82.93; H, 10.72; N, 1.93; Found: C, 82.25, H, 10.60, N, 2.11. ESIMS: $\mathrm{m} / \mathrm{z}=724.20$ observed for $\mathrm{M}^{+} ; 724.16$ calculated.

We note that the chloromethyl akoxyamine $\mathbf{3}$ can also be used in place of $\mathbf{4}$. In our hands, the reaction between $\mathbf{3}$ and the $\mathrm{K}$ salt of cholesterol (synthesized via reaction of $\mathrm{KH}$ and cholesterol) also works.

Preparation of Cholesterol-Attached Poly(acrylic acid) 7. To a 5-mL conical Pyrex reaction vessel (thick-wall glass used in commercial microwave synthesis, obtained from either Biotage or CEM) equipped with a magnetic stirbar was added a mixture of the cholesterol-attached alkoxyamine $5(49.4 \mathrm{mg}, 68.27 \mu \mathrm{mol})$, nitroxide radical 2 (0.86 mg, $3.41 \mu \mathrm{mol})$, and tert-butyl acrylate (4.375 g, $34.13 \mathrm{mmol})$. The resulting solution was sealed with a ruber septum, degassed by three times freeze/thaw cycles using a 18 -gauge needle, and heated at $120{ }^{\circ} \mathrm{C}$ for 9 hours under nitrogen. After cooling down to room temperature, the reaction content was tranferred into a 25 - 
$\mathrm{mL}$ round-bottom flask and the remaining monomers were removed by rotary evaporator. The crude rubbery solid product was redissolved in a minimum amount of dichloromethane and then precipitated by addition of a methanol/water $(8: 2 \mathrm{v} / \mathrm{v})$ mixture. The molecular weight of the cholesterol-attached poly(tert-butyl acrylate) 6 was measured by gel permeation chromatography $(\mathrm{GPC}): \mathrm{M}_{\mathrm{n}}=3.8$ $\mathrm{kDa}, \mathrm{DP}=24$ taking into account the mass of the initiator, $\mathrm{M}_{\mathrm{w}} / \mathrm{M}_{\mathrm{n}}=1.097$ (Figure S2). A DP of 24 was independently obtained by ${ }^{1} \mathrm{H}$ NMR integration of the cholesterol (Figure S3).

For acidolysis, the resulting polymer $6(\sim 190 \mathrm{mg}, 50 \mu \mathrm{mol})$ was dissolved in dichloromethane $(10 \mathrm{~mL})$ and a 5-fold molar excess of trifluoroacetic acid (TFA) was added followed by stirring at room temperature for 15 hours. During acidolysis, the rubbery PAA slowly precipitated out of the solution. After removal of dichloromethane and TFA by rotary evaporator, the cholesterol-attached poly(acrylic acid) product (Chol-PAA, 7) was dissolved in nanopure water $(3 \mathrm{~mL})$ by adjusting the $\mathrm{pH}$ to 7.0 with aqueous $\mathrm{NaOH}(1 \mathrm{M})$ and purified by dialysis $(\mathrm{MWCO}=2000,3-\mathrm{mL}$ membrane tube) against nanopure water $(14 \mathrm{x} 1000 \mathrm{~mL})$ for a week with water change in every $12 \mathrm{~h}$. After dialysis, water was removed from the product solution (inside the membrane) by lyophilization to give the product as a colorless rubber $\left(23.2 \mathrm{mg}, 9.28 \mu \mathrm{mol}, \mathrm{M}_{\mathrm{n}}=2.5 \mathrm{kDa}\right.$ taking into account the mass of the initiator). The attachment of cholesterol and removal of tert-butyl group were confirmed by ${ }^{1} \mathrm{H}$ NMR after acidolysis (Figure S3). A differential scanning calorimetry scan of the polymer (from $30{ }^{\circ} \mathrm{C}$ to $150{ }^{\circ} \mathrm{C}$ at $10{ }^{\circ} \mathrm{C} / \mathrm{min}$ ) exhibited only a transition at $92.4{ }^{\circ} \mathrm{C}$, which, together with the ${ }^{1} \mathrm{H}$-NMR data, suggests that the cholesterol $\left(\mathrm{T}_{\mathrm{m}}=148{ }^{\circ} \mathrm{C}\right)$ is covalently bonded to the polymer. The resulting Chol-PAA was dissolved in nanopure water $(1 \mathrm{~mL})$ by adjusting the pH to 7.4 with aqueous $\mathrm{NaOH}(1 \mathrm{M})$ to give the final concentration of $9.28 \mathrm{mM}$.

We note that Chol-PAA will self-aggregate to form micelles in water. The 2.5 -kDa polymer yielded micelles with $D_{\mathrm{H}}=15 \pm 3 \mathrm{~nm}$ and the 5.6-kDa polymer yielded micelles with $D_{\mathrm{H}}=27 \pm 5 \mathrm{~nm}$. However, these micelles are easily dispersed in the presence of a small amount of Triton-X or in the presence of liposomes.

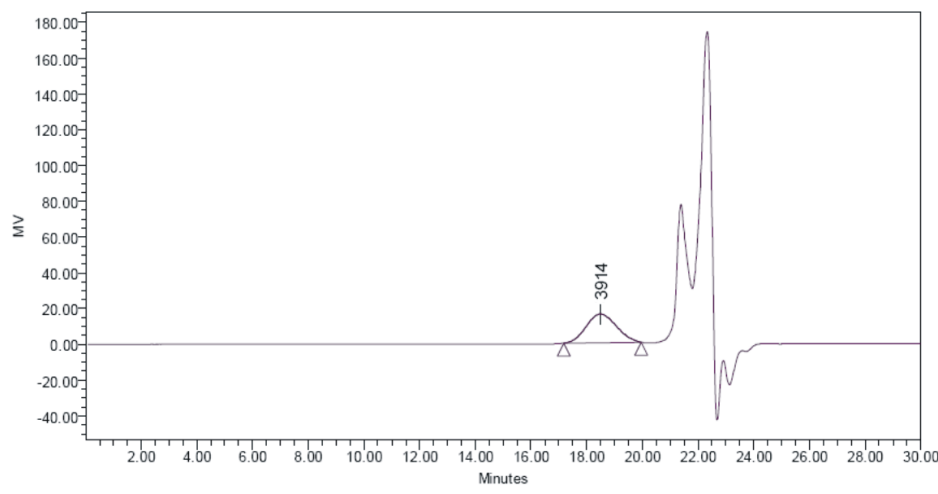

Figure S2. Gel permeation chromatogram of cholesterol-terminated poly(tert-butyl acrylate) $\left(\mathrm{M}_{\mathrm{n}}=3.8 \mathrm{kDa}, \mathrm{M}_{\mathrm{w}} / \mathrm{M}_{\mathrm{n}}=1.09\right)$.

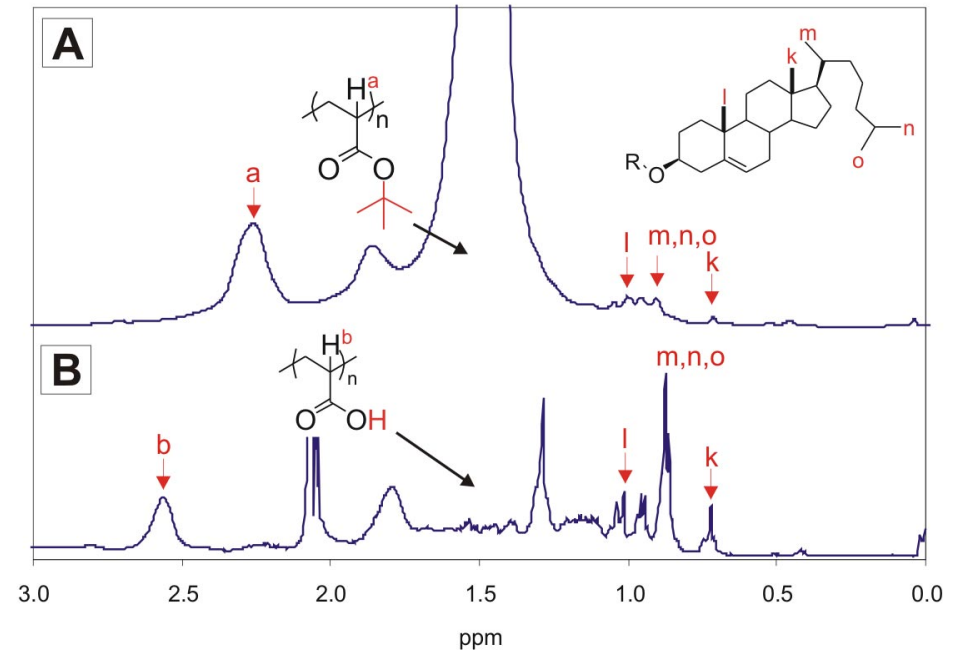

Figure S3. ${ }^{1} \mathrm{H}$ NMR spectra of poly(tert-butyl acrylate) before (A) and after (B) acidolysis. Acidolysis was confirmed by the absence of proton peak at $1.5 \mathrm{ppm}$ from the tert-butyl groups and downfield shift of proton peak from ' $\mathrm{a}$ ' at $2.2 \mathrm{ppm}$ to 'b' at $2.6 \mathrm{ppm}$. Attachment of cholesterol-end group was also observed (proton ' $\mathrm{k}, 1, \mathrm{~m}, \mathrm{n}$, and o').

Liposome Preparation. All liposomes were made from a mixture of DPPC/DOPG/Cholesterol (51.4/3.6/45, mol\% ratio) using a modification of a general preparative procedure for liposomes. To a glass vial $(15 \mathrm{x} 45 \mathrm{~mm})$ was added DPPC (4.55 mg), DOPG $(0.35$ $\mathrm{mg}$ ), and cholesterol $(2.1 \mathrm{mg})$, followed by chloroform $(0.3 \mathrm{~mL})$ to make a colorless solution. After vortexing (30 sec), the solvent was 
removed by passing a stream of nitrogen over the solution while the vial was warmed in a $50-{ }^{\circ} \mathrm{C}$ water bath. The resulting dry film was further dried under vacuum on a Schlenk line (30 mTorr) for one hour. Next, the dry lipid films were hydrated in 10-mM PIPES buffer solution $(300 \mu \mathrm{L}, \mathrm{pH} 7.4,150 \mathrm{mM} \mathrm{NaCl})$ followed by vigorous vortex (3-5 min) to form a dispersion of multilamellar vesicles (MLVs). After they were subjected to 10 freeze-thaw cycles, the resulting dispersion of MLVs was extruded ten times through two stacked polycarbonate extrusion membranes (100-nm pore-size) that are maintained at $50{ }^{\circ} \mathrm{C}$ on an extruder block. ${ }^{4}$ At the end, the initial vial and syringes were washed with an additional aliquot of PIPES buffer $(100 \mu \mathrm{L})$ and this wash was also extruded ten times. The combined solution $(\sim 400 \mu \mathrm{L})$ contain liposomes with a mean hydrodynamic diameter of $82 \pm 14 \mathrm{~nm}(\mathrm{PDI}=0.046 \pm 0.021)$ as determined by DLS measurements (Figure S4). The final concentration of lipids was $19.25 \mathrm{mM}(7.7 \mu \mathrm{mol})$ as determined by phosphorous ICP-OES.

Preparation of Polymer-Incorporated Liposomes (PILs). To a liposome solution (100 $\mu \mathrm{L}, 1.925 \mu$ mol), prepared as described above, was added Chol-PAA solution $(20.7 \mu \mathrm{L}, 192.5 \mathrm{nmol}, 10 \mathrm{~mol} \%$ relative to the lipid concentration) and incubated at room temperature overnight. ${ }^{5}$ Possible free unbound polymers were removed by passing the incubated solution through a Sephadex G-50 column (fraction range: $1,500-30,000 \mathrm{Da}, 2 \mathrm{~cm} \times 7 \mathrm{~cm})$ that was wet-packed and pre-equilibrated with 10-mM PIPES solution (pH 7.4, $150 \mathrm{mM} \mathrm{NaCl})$. The eluant was also 10-mM PIPES solution and the fractions was collected every 5 drops. The PIL-containing fractions can be easily recognized by their turbidity and combined together $(\sim 1.5 \mathrm{~mL})$. The hydrodynamic diameter $\left(D_{\mathrm{H}}\right)$ of the PIL increased to $93 \pm 15 \mathrm{~nm}$ $(\mathrm{PDI}=0.047 \pm 0.016)$ (Figure S4). The final concentration of lipids was $1.058 \mathrm{mM}$ as determined by phosphorous ICP-OES.

As a comparison, Chol-PAA with a 5.6- $\mathrm{kDa} \mathrm{M}_{\mathrm{n}}$ was also prepared and combined with the same BLs. DLS measurements of the resulting PILs revealed a mean $D_{\mathrm{H}}$ of $128 \pm 22 \mathrm{~nm}(\mathrm{PDI}=0.052 \pm 0.021)$.

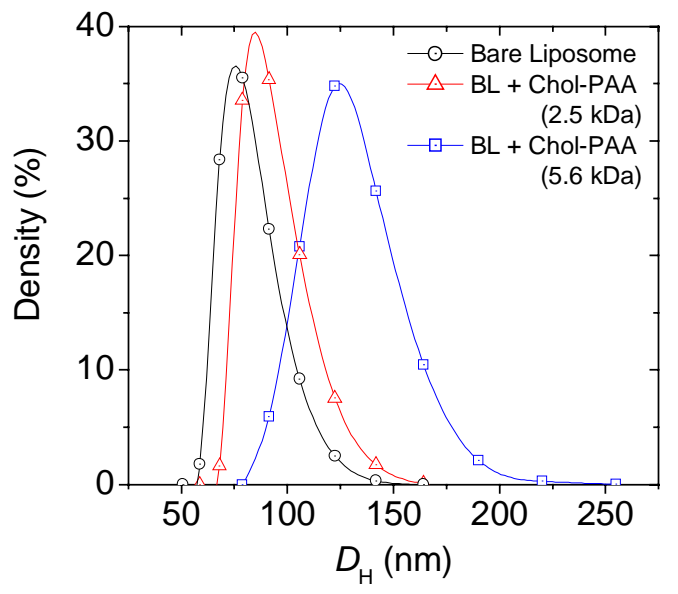

Figure S4. Hydrodynamic diameters $\left(D_{\mathrm{H}}\right)$ of BLs and PILs measured by dynamic light scattering (DLS). Addition of Chol-PAA $(2.5 \mathrm{kDa})$ to BLs (mean $D_{\mathrm{H}}=82 \pm 14 \mathrm{~nm}$ ) formed PILs with increased mean $D_{\mathrm{H}}$ of $93 \pm 15 \mathrm{~nm}$. Addition of Chol-PAA ( $5.6 \mathrm{kDa}$ ) to the same BLs formed PILs with a larger mean $D_{\mathrm{H}}$ of $128 \pm 22 \mathrm{~nm}$.

For the preparation of polymer-caged liposomes below, an upper limit for the number of carboxylic acid residues on PILs was calculated from the final concentration of lipids in PILs, assuming 100\% incorporation of the Chol-PAA additive. This is a reasonable assumption given the well-known tendency of cholesterol to insert into lipid bilayers. ${ }^{5-12}$ Indeed, up to $0.82 \mathrm{~mol} / \mathrm{mol} \mathrm{ratio}$ of cholestrol/phospholipid was reported in humane plasma membrane ${ }^{13,14}$ and it was observed that up to 35 mol\% of the cholesterol-modified PEG-derivatives was inserted into the outer membrane of $100-\mathrm{nm}$ preformed liposome using post-insertion method. ${ }^{5}$ In our case, maximum cholestrol mol\% in outer layer was less than $35 \mathrm{~mol} \%$.

Preparation of Polymer-Caged Liposomes (PCLs). EDC·MeI (1.0 mg, $3.365 \mu \mathrm{mol})$ was dissolved in 10-mM PIPES buffer (500 $\mu \mathrm{L}$, pH $7.4,150 \mathrm{mM} \mathrm{NaCl})$ to give a $6.73-\mathrm{mM}$ EDC $\cdot$ MeI solution. This EDC $\cdot$ MeI solution $(300 \mu \mathrm{L}, 2.019 \mu \mathrm{mol}, \sim 4.0$ equiv to the total number of carboxylic acid groups (507.8 nmol) assuming $100 \%$ incorporation of the Chol-PAA additive) was added to a disposable culture tube (13 mm x $100 \mathrm{~mm}$, Fisher Scientific) containing an aliquot $(200 \mu \mathrm{L}, 211.6 \mathrm{nmol})$ of the previously prepared PIL solution (vide supra) to activate the carboxylic acids in PAA residue outside PILs. After $20 \mathrm{~min}, 2,2$ '-(ethylendioxy)bis(ethylamine) (127.0 nmol, 0.25 equiv to the total carboxylic acid groups for a theoretical 50\% crosslinking) was added and the mixture was capped with parafilm and left overnight. The byproducts were removed by dialysis ( $\mathrm{MWCO}=10,000,1-\mathrm{mL}$ membrane tube) against $10-\mathrm{mM}$ PIPES buffer $(6 \mathrm{x} 500 \mathrm{~mL}$, $\mathrm{pH} 7.4,150 \mathrm{mM} \mathrm{NaCl}$ ) for 3 days with buffer change in every $12 \mathrm{~h}$. The final concentration of lipids was $461.8 \mu \mathrm{M}$ as determined by phosphorous ICP-OES. The hydrodamic diamters were compared before and after crosslinking by DLS measurements (Figure S5).

For lyophilization, an aliquot $(500 \mu \mathrm{L}, 461.8 \mu \mathrm{M})$ of the as-prepared PCL solution was placed into a 5-mL vial and frozen in liquid nitrogen before drying under vacuum (either in a lyophylizer or on a Schlenk line). The residual solid was rehydrated with nanopure water $(500 \mu \mathrm{L})$ followed by vortexing $(10 \mathrm{~min})$. The rehydrated samples were observed by both DLS and TEM (Figure S6). For the spectroscopic measurements, PCLs were prepared in nanopure water and lyophilized under vacuum. The resulting solid powder of PCLs was observed by FTIR (Figure S7) and then rehydrated in $\mathrm{D}_{2} \mathrm{O}$ for ${ }^{1} \mathrm{H}-\mathrm{NMR}$ measurements (Figure S8).

The molecular weights of crosslinked polymer-shell in PCLs and non-crosslinked Chol-PAA anchored on PILs were compared by gel filtration chromatography (Figure S9). Liposome templates in both PCLs and PILs were broken up by addition of a 5\% aqueous solution 
of Triton X-100 (5 $\mu \mathrm{L})$ and the resulting solution was manually injected into the gel filtration chromatograph (GFC). Calibration curve was obtained from four linear PAA standards (Figure S9) and the molecuar weights of samples were calculated from the calibration curve.

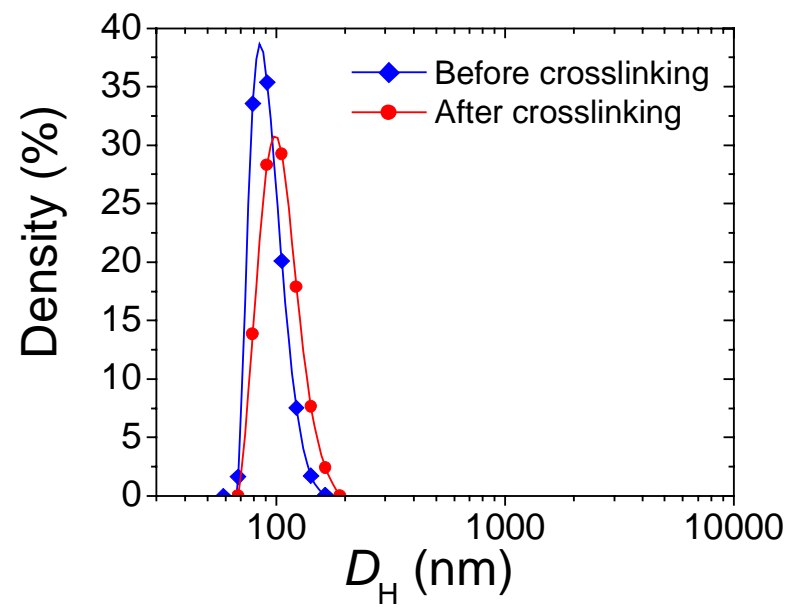

Figure S5. Hydrodynamic diameters $\left(D_{\mathrm{H}}\right)$ of PILs and PCLs measured by dynamic light scattering (DLS).
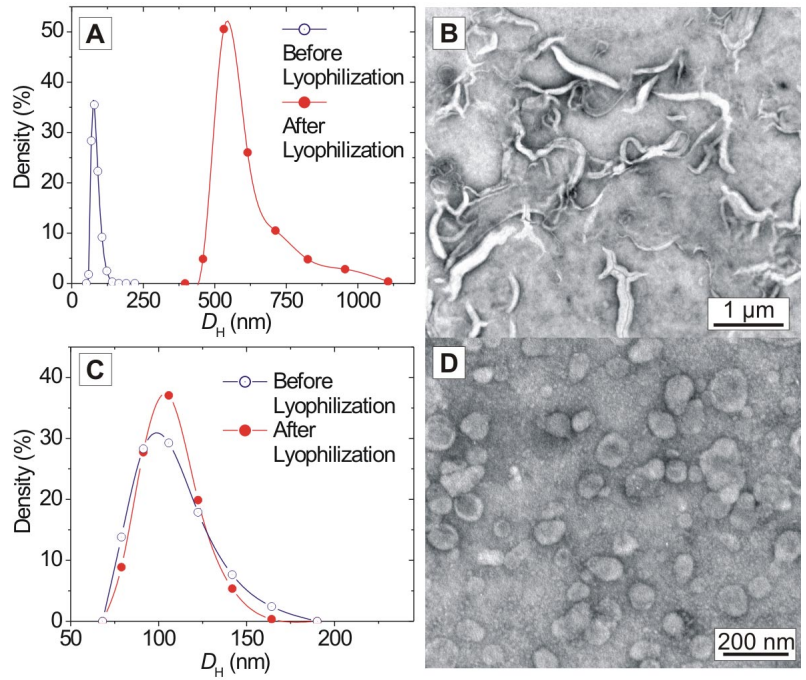

Figure S6. Hydrodynamic diameter $\left(D_{\mathrm{H}}\right)$ of (A) BLs and (C) PCLs before (-०-) and after (-•-) lyophilization/rehydration. TEM images of (B) BLs and (D) PCLs after lyophilization/rehydration. All samples were negatively stained with $4 \%$ aqueous uranyl acetate for TEM observation. 

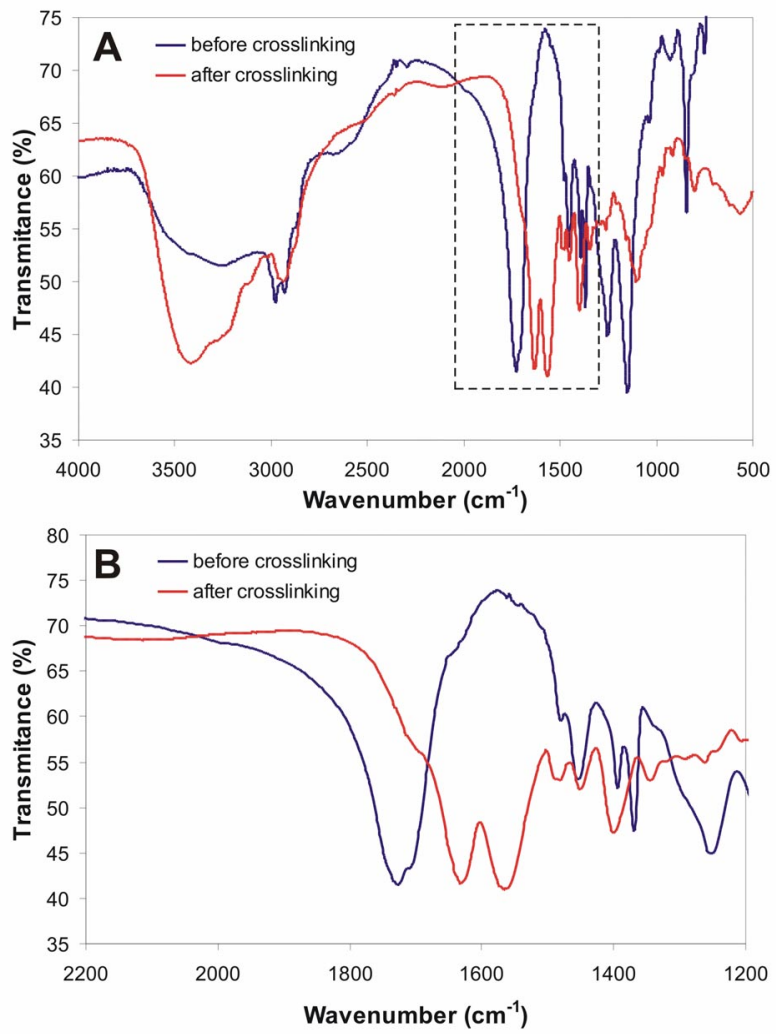

Figure S7. (A) FT-IR spectra of PILs (before crosslinking) and PCLs (after crosslinking) in KBr. (B) Zoomed-in region between 1200 and $2200 \mathrm{~cm}^{-1}$.

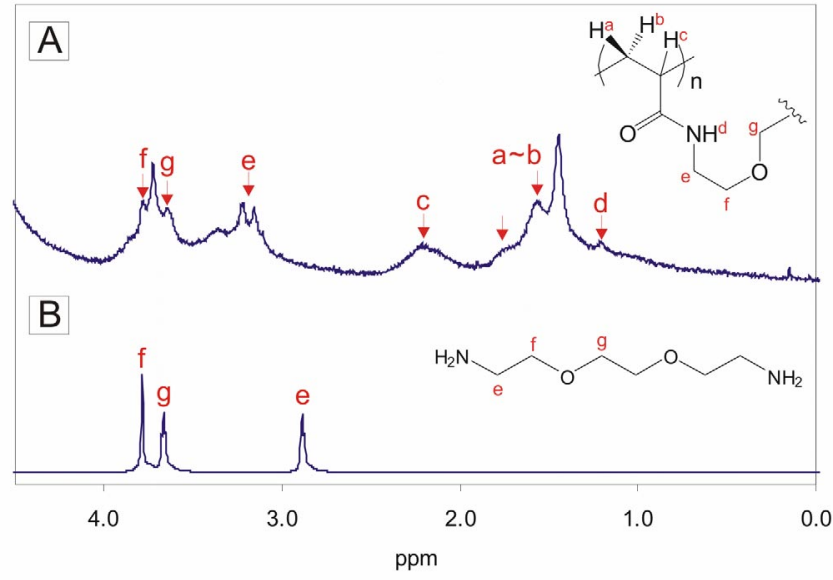

Figure S8. Water-suppressed ${ }^{1} \mathrm{H}$ NMR spectra of (A) PCLs and (B) free diamine crosslinker. After crosslinking, proton resonance 'e' was shifted to downfield to $3.2 \mathrm{ppm}$ (from $2.9 \mathrm{ppm}$ ). 

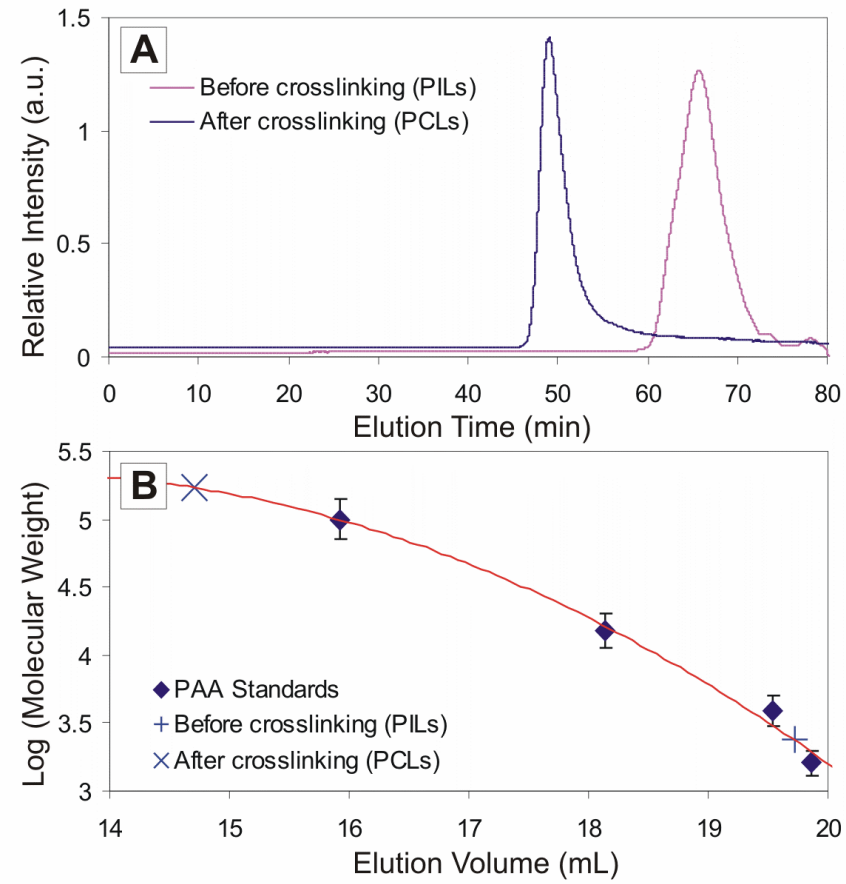

Figure S9. (A) Gel filtration chromatogram of polymer-incorporated liposomes before and after crosslinking. (B) Semilogarithmic calibration plot of apparent "polymer molecular weight" versus elution volume. Calibration curve was obtained from PAA standards. The large difference in "apparent molecular weights" between PILs and PCLs can be seen by plotting their respective elution volumes on this calibration curve, assuming that the effect of the TritonX100 on the migration of the PCL shells is minimal.

Calcein Release Assay. Using the same procedure reported above, a dry lipid film was hydrated in an aqueous calcein solution $(300 \mu \mathrm{L}$, $75 \mathrm{mM}, \mathrm{pH}$ was adjusted to 7.4 with aqueous $\mathrm{NaOH}(1 \mathrm{M})$ ) to form the calcein-containing liposomes. Free calcein molecules were separated from the vesicles by Sephadex G-50 column equilibrated with 10-mM PIPES solution (pH 7.4, $150 \mathrm{mM} \mathrm{NaCl})$. Preparations of calcein-containing PILs and PCLs were carried out exactly as described above.

For the plasma stability test, calcein-containing vesicle solution was mixed with fetal bovine serum in a 1:9 or $5: 5 \mathrm{v} / \mathrm{v}$ ratio (the concentration of lipid was $36.94 \mu \mathrm{M}$ ) and incubated at $37{ }^{\circ} \mathrm{C}$ in a capped 5-mL vial. The fluorescence from the liposome-encapsulated calcein was self-quenched due to its high concentration inside the vescicle. Hence, only the fluorescence from the dye that has leaked out of the ruptured liposome was measured. ${ }^{15}$ Aliquots $(20 \mu \mathrm{L})$ were withdrawn as a function of incubation time, diluted in 10-mM PIPES buffer $(980 \mu \mathrm{L}, \mathrm{pH} 7.4,150 \mathrm{mM} \mathrm{NaCl})$, and the calcein leakage was observed by fluorescence spectroscopy. Afterward, $5 \%$ aqueous Triton X-100 $(5.0 \mu \mathrm{L})$ was then added to totally break up the liposomes and the total calcein fluorescence was measured to give the $100 \%$ release value. The extent of leakage was observed by comparing the release ratio of leaked dye to the maximum release value determined by addition of 5\% aqueous Triton X-100 $(5.0 \mu \mathrm{L})$ to the initial solution (time $=0) .{ }^{16}$ The percent leakage was calculated as:

$$
\% \text { Leakage }=\frac{\left(F_{t} / F_{t}^{T}-F_{0} / F_{0}{ }^{T}\right)}{\left(1-F_{0} / F_{0}{ }^{T}\right)} \times 100
$$

where $F_{t}=$ fluorescence intensity at time $t ; F_{0}=$ fluorescence intensity at time zero; $F_{t}^{T}=$ maximum fluorescence intensity in the presence of Triton X-100 at time $t ; F_{0}{ }^{T}=$ maximum fluorescence intensity in the presence of Triton X-100 at time zero.

For the acid-induced release assay, a $5-\mathrm{mL}$ vial containing an aliquot of the calcein-containing vesicle solution $(1.0 \mathrm{~mL}, 199.2 \mu \mathrm{M})$ were incubated in 50-mM acetate buffer $(\mathrm{pH} 4.0,150 \mathrm{mM} \mathrm{NaCl})$ and 50 -mM MES buffer $(\mathrm{pH} 5.5,150 \mathrm{mM} \mathrm{NaCl})$ at $37{ }^{\circ} \mathrm{C}$ and the fluorescence was measured as a function of incubation time as described above. As the pKa's of the carboxylic acid groups in calcein are 2.1, 2.9, 4.2, and 5.5, respectively, protonation of these groups at low $\mathrm{pH}$ may render calcein more hydrophobic and decrease the release rate of calcein into solution.

General Considerations. Instruments in the Northwestern NUANCE and ASL facilities were purchased with grants from NSF-NSEC, NSF-MRSEC, Keck Foundation, the state of Illinois, and Northwestern Univ. We thank Profs. Chad A. Mirkin and Phillip B. Messersmith for the use of the DLS (Mirkin), fluorimetric (Mirkin), and gel-filtration (Messersmith) instruments

Fourier-transformed nuclear magnetic resonance (NMR) spectroscopy was performed on a Varian INOVA-500 MHz spectrometer. Chemical shifts of ${ }^{1} \mathrm{H}$ NMR spectra are reported in ppm against residual solvent resonance as the internal standard $\left(\mathrm{CDCl}_{3}=7.27 \mathrm{ppm}\right.$, acetone- $\left.d_{6}=2.05 \mathrm{ppm}, \mathrm{D}_{2} \mathrm{O}=4.80 \mathrm{ppm}\right) .{ }^{1} \mathrm{H}$ NMR data are reported as follows: chemical shift (multiplicity $(\mathrm{s}=$ singlet, $\mathrm{d}=$ doublet, $\mathrm{t}=$ triplet, $\mathrm{q}=$ quartet, and $\mathrm{m}=$ multiplet), integration, assignments, coupling constant). Fourier-transformed infrared (FTIR) spectroscopy 
was performed on a Bio-Rad FTS-60 FTIR. FTIR spectra of small-molecule compounds were measured on the NaCl plates carried by $\mathrm{CH}_{2} \mathrm{Cl}_{2}$. KBr-pellets were prepared for FTIR measurements of lyophilized liposome samples. Electrospray-ionization mass spectrometric (ESI-MS) data were obtained on a Micromass Quattro II triple quadrupole mass spectrometer. Phosphorus concentration was determined using a Varian Vista MPX simultaneous inductively coupled plasma optical emission spectrometer (ICP-OES). Elemental analyses were provided by Atlantic Microlab, Inc. (Norcross, GA). Differential Scanning Calorimetry (DSC) was performed on a Mettler-Toledo DSC822e with a $\mathrm{N}_{2}$ atmosphere.

Polymer molecular weights were measured relative to polystyrene standards on a Waters gel-permeation chromatograph (GPC) equipped with Breeze software, a 717 autosampler, Shodex KF-G guard column, KF-803L and KF-806L columns in series, a Waters 2440 UV detector, and a 410 RI detector. HPLC-grade THF was used as an eluent at a flow rate of $1.0 \mathrm{~mL} / \mathrm{min}$ and the instrument was calibrated using polystyrene standards (Aldrich, 15 standards, 760-1,800,000 Daltons). Gel-filtration chromatography (GFC) was carried out on a Waters chromatograph (three Shodex polyhydroxymethacrylate gel columns OHpak SB-802HQ, SB-802.5HQ, and SB-804HQ columns in series) connected to a Waters $410 \mathrm{RI}$ detector with $50-\mathrm{mM}$ phosphate buffer ( $\mathrm{pH} 7.0,50 \mathrm{mM} \mathrm{NaCl}$ ) as an eluent at a flow rate of $0.3 \mathrm{~mL} / \mathrm{min}$. In measuring the molecular weight (MW) of Chol-PAA, extracted Chol-PAA from PILs, and crosslinked polymer shell from PCLs, a GFC calibration curve was plotted using four different poly(acrylic acid) (PAA) standards (Aldrich Chemicals, molecular weights $=2.1,5.1,15$, and $100 \mathrm{kDa}$ ). The MW of each experimental sample was then calculated using this calibration curve (Figure S9).

Dynamic light scattering (DLS) measurements were performed on a Zetasizer Nano ZS (Marvern Instruments, Malvern, UK) with a HeNe laser $(633 \mathrm{~nm})$. Non-invasive backscatter method (detection at $173^{\circ}$ scattering angle) was used. Correlation data were fitted-using the method of cumulants - to the logarithm of the correlation function, yielding the diffusion coefficient, $D$. The hydrodynamic diameters $\left(D_{\mathrm{H}}\right)$ of the nanoparticles (BLs, PILs, and PCLs) were calculated using $D$ and the Stokes-Einstein equation $\left(D_{\mathrm{H}}=k_{B} T / 3 \pi \eta D\right.$, where $k_{B}$ is the Boltzmann constant, $T$ is the absolute temperature, and $\eta$ is the solvent viscosity $(\eta=0.8872 \mathrm{cP}$ for water)). The polydispersity index (PDI) of liposomes-represented as $2 c / b^{2}$, where $b$ and $c$ are first and second order coefficients, respectively, in a polynomial of a semi-log correlation function - was calculated by the cumulants analysis. Size distribution of vesicles was obtained by the non-negative least squares (NNLS) analysis. ${ }^{17}$ Unless noted otherwise, all samples were dispersed in 10-mM PIPES solution (pH 7.4, $150 \mathrm{mM} \mathrm{NaCl}$ ) for DLS measurements. The data reported represent an average of ten measurements with five scans each.

Transmission electron microscopy (TEM) was performed on a Hitachi H8100 microscope operating at an accelerating voltage of 200 $\mathrm{kV}$. All samples were negatively stained with 4-wt\% aqueous uranyl acetate. Fluorescence emission spectra were obtained on a Jobin Yvon-SPEX Fluorolog fluorometer $\left(\lambda_{\mathrm{ex}}=470 \mathrm{~nm}, \lambda_{\mathrm{em}}=514 \mathrm{~nm}\right)$.

Clarifications regarding the indented structure of liposomes in TEM observations.

The indented morphology in Figures $1 \mathrm{~B}$ and $1 \mathrm{C}$ is commonly observed in the high-vacuum environment of the TEM experiment, which deflated the liposomes via evaporation of the aqueous cores and yielded the indented morphology. Because the TEM-induced indentation usually occurs on one side of the sphere, the particle will be seen as a flat disk if the indented side is faced down. For bare liposomes (Figure 1A), the particles on the top right corner are indented in the same manner as those shown in Figures 1B and 1C; however, the remaining particles appear "flat, more intact" because their indented side faced down. This situation is commonly seen in the literature for both bare ${ }^{18}$ and modified liposomes. ${ }^{19}$

\begin{abstract}
Additional clarifications for the hypotheses mentioned in the manuscript for the acid-triggered release mechanism in PCLs. Regarding the first hypothesis for enhanced released of payload in PCLs comparing to PILs. The polymer "shell" in our PIL essentially comprised of poly(acrylic acid) chains while the shell in our PCL is a network of poly(acrylic acid) chains with $N$-alkyl acrylamide crosslinks. These two systems behaved very differently under changing $\mathrm{pH}$. Above the lower critical solution temperature (LCST), poly( $N$-alkyl acrylamide) aggregates in aqueous solution through a phase transition because the hydrophobic groups in the polymer forms insoluble aggregates. ${ }^{2,21}$ When this polymer is partially hydrolyzed, the resulting poly(acrylic acid)-co-(acrylamide) network is a well-known hydrogel that swells and shrinks repeatedly depending on the solvent composition, slat conc., temperature and $\mathrm{pH}$ of solution. $^{22}$ Especially, the $\mathrm{pH}$-dependent ionization of the carboxylic acid groups in this polymer was shown to play a crucial role in volume shrinking of polymer network at low $\mathrm{pH}$ following Flory-Huggins theory. ${ }^{23}$ The critical $\mathrm{pH}$ for the phase transition of the hydrogel at a given temperature can be tuned by varying the ratio of acrylic acid groups to acrylamide groups in a polymer chain. ${ }^{20}$ If this ratio is too high, the polymer looses hydrogel property due to insufficient hydrophobicity for aggregation. In contrast, poly(acrylic acid) does not show hydrogel properties under acidic condition, but shows a continuous conformational change due to the protonation of acid groups. ${ }^{24}$

The aforementioned arguments clearly suggest that the $\mathrm{pH}$-dependence of our PILs should follow that of poly(acrylic acid). Continuous conformational changes of "free," non-crosslinked poly(acrylic acid) on the surface of PILs as the carboxylic acid groups being protonated at low $\mathrm{pH}$ should not cause stress on the underlying lipid bilayer. On the other hand, the $N$-acrylamide-crosslinked network on the surface of our PCLs should undergo hydrogel-like phase transitions at low pH, result in significant "squeeze" of the lipid shells, and potentially disrupt the core, releasing the payload.
\end{abstract}

Regarding the second hypothesis for enhanced released of payload in PCLs comparing to PILs. Seki and Tirrell has examined the interactions of poly(acrylic acid) with liposomes under variable acidity. ${ }^{25}$ They showed that increased acidity can favor hydrogen-bonded interactions between the carboxylic acid groups in the polymer and the phosphodiester headgroups of the lipid molecules in the membrane, decreasing the lipid-lipid interactions that are responsible for membrane stabilization. In this sense, there should be no difference between the poly(acrylic acid) chains in our PILs and PCLs. However, the $N$-alkyl acrylamide crosslinks in the PCLs should constrain the degree of freedoms of the poly(acrylic acid) chains, keeping them closer to the surface of the lipid bilayer and allowing for more favorable interactions between the acrylic acid groups and the phosphodiester head groups.

\section{References}

(1) Benoit, D.; Chaplinski, V.; Braslau, R.; Hawker, C. J. J. Am. Chem. Soc. 1999, 121, 3904-3920.

(2) Pangborn, A. B.; Giardello, M. A.; Grubbs, R. H.; Rosen, R. K.; Timmers, F. J. Organometallics 1996, 15, $1518-1520$.

(3) Dao, J.; Benoit, D.; Hawker, C. J. J. Polym. Sci. Pol. Chem. 1998, 36, 2161-2167.

(4) Szoka, F.; Olson, F.; Heath, T.; Vail, W.; Mayhew, E.; Papahadjopoulos, D. Biochim. Biophys. Acta-Biomembr. 1980, 601, $559-571$. 
(5) Menger, F. M.; Zhang, H. J. Am. Chem. Soc. 2006, 128, 1414-1415.

(6) Mauk, M. R.; Gamble, R. C.; Baldeschwieler, J. D. Proc. Natl. Acad. Sci. U.S.A. 1980, 77, 4430-4434.

(7) Wu, P.-S.; Wu, H.-M.; Tin, G. W.; Schuh, J. R.; Croasmun, W. R.; Baldeschwieler, J. D.; Shen, T. Y.; Ponpipom, M. M. Proc. Natl. Acad. Sci. U.S.A. 1982, 79, 5490-5493.

(8) Patel, K. R.; Li, M. P.; Schuh, J. R.; Baldeschwieler, J. D. Biochim. Biophys. Acta-Biomembr. 1985, 814, 256-264.

(9) Sunamoto, J.; Sato, T.; Hirota, M.; Fukushima, K.; Hiratani, K.; Hara, K. Biochim. Biophys. Acta-Biomembr. 1987, 898, 323-330.

(10) Booth, C.; Bushby, R. J.; Cheng, Y.; Evans, S. D.; Liu, Q.; Zhang, H. Tetrahedron 2001, 57, 9859-9866.

(11) Bergstrand, N.; Arfvidsson, M. C.; Kim, J.-M.; Thompson, D. H.; Edwards, K. Biophys. Chem. 2003, 104, 361-379.

(12) Pfeiffer, I.; Hook, F. J. Am. Chem. Soc. 2004, 126, 10224-10225.

(13) Lange, Y.; Swaisgood, M. H.; Ramos, B. V.; Steck, T. L. J. Biol. Chem. 1989, 264, 3786-3793.

(14) Lange, Y.; Ye, J.; Steck, T. L. Proc. Natl. Acad. Sci. U. S. A. 2004, 101, 11664-11667.

(15) Allen, T. M.; Cleland, L. G. Biochim. Biophys. Acta-Biomembr. 1980, 597, 418-426.

(16) Holland, J. W.; Hui, C.; Cullis, P. R.; Madden, T. D. Biochemistry 1996, 35, 2618-2624.

(17) Stock, R. S.; Ray, W. H. J. Polym. Sci. Pt. B-Polym. Phys. 1985, 23, 1393-1447.

(18) Liu, Y.; Regen, S. L. J. Am. Chem. Soc. 1993, 115, 708-713.

(19) Sideratou, Z.; Foundis, J.; Tsiourvas, D.; Nezis, I. P.; Papadimas, G.; Paleos, C. M. Langmuir 2002, 18, 5036-5039.

(20) Chen, G.; Hoffman, A. S. Nature 1995, 373, 49-52.

(21) Nayak, S.; Lyon, L. A. Angew. Chem., Int. Ed. 2005, 44, 7686-7708.

(22) Ricka, J.; Tanaka, T. Macromolecules 1984, 17, 2916-2921.

(23) Tanaka, T.; Fillmore, D.; Sun, S.-T.; Nishio, I.; Swislow, G.; Shah, A. Phys. Rev. Lett. 1980, 45, 1636.

(24) Garces, J. L.; Koper, G. J. M.; Borkovec, M. J. Phys. Chem. B 2006, 110, 10937-10950.

(25) Seki, K.; Tirrell, D. A. Macromolecules 1984, 17, 1692-1698. 